\title{
Glutamate Receptor Subunit 2 Serine 880 Phosphorylation Modulates Synaptic Transmission and Mediates Plasticity in CA1 Pyramidal Cells
}

\author{
Kenneth J. Seidenman, ${ }^{1}$ Jordan P. Steinberg, ${ }^{2}$ Richard Huganir, ${ }^{2}$ and Roberto Malinow ${ }^{1}$ \\ ${ }^{1}$ Cold Spring Harbor Laboratory, Cold Spring Harbor, New York 11724, and ${ }^{2}$ Howard Hughes Medical Institute, Department of Neuroscience, Johns \\ Hopkins University, Baltimore, Maryland 21205
}

\begin{abstract}
The cytoplasmic C termini of AMPA receptor subunits contain PDZ (postsynaptic density 95/Discs large/zona occludens 1) ligand domains that can control their synaptic trafficking during plasticity. The glutamate receptor subunit 2 (GluR2) PDZ ligand domain can be phosphorylated at serine 880 (S880), and this disrupts interactions with GRIP/ABP (glutamate receptor-interacting protein/AMPAbinding protein) but not with PICK1 (PKC-interacting protein 1). Here, the impact of GluR2 S880 phosphorylation on synaptic transmission and plasticity was explored by expressing, in hippocampal slice cultures, GluR2 subunits containing point mutations that mimic or prevent phosphorylation at this residue. Our results indicate that mimicking GluR2 S880 phosphorylation excludes these receptors from synapses, depresses transmission, and partially occludes long-term depression (LTD). Conversely, mutations that prevent phosphorylation reduce LTD. Disruption of the interaction between GluR2 and GRIP/ABP by $S 880$ phosphorylation may thus facilitate removal of synaptic AMPA receptors and mediate some forms of activity-dependent synaptic depression.
\end{abstract}

Key words: AMPA; LTD; hippocampus; synapse; plasticity; trafficking

\section{Introduction}

AMPA receptor traffic is critical to the establishment, maintenance, and plasticity of glutamatergic synapses in the CNS. AMPA receptors (AMPA-Rs) are tetrameric (Rosenmund et al., 1998) hetero-oligomers composed of combinations of glutamate receptor (GluR) subunits 1-4 (Seeburg, 1993; Hollmann and Heinemann, 1994; Dingledine et al., 1999). In the adult hippocampus, the AMPA receptor population is composed primarily of GluR1/GluR2 and GluR2/GluR3 heteromers (Wenthold et al., 1996). A number of studies indicate that the synaptic delivery of different subunit combinations is governed by molecular rules encoded in the intracellular C-tails of the receptor subunits. GluR1/GluR2 heteromers, as well as GluR1 homomers, are driven into synapses by strong depolarizing stimuli capable of activating calcium/calmodulin-dependent protein kinase II (Shi et al., 1999; Hayashi et al., 2000; Passafaro et al., 2001). In contrast, GluR2/GluR3 heteromers (as well as GluR2 homomers) constitutively recycle at AMPA-R-containing synapses, on a relatively rapid time scale, without a requirement for synaptic transmission (Osten et al., 1998; Song et al., 1998; Luscher et al., 1999; Luthi et al., 1999; Malinow et al., 2000; Shi et al., 2001).

The C terminus of GluR2 encompasses several protein-pro-

\footnotetext{
Received June 4, 2003; revised Aug. 18, 2003; accepted Aug. 19, 2003.

This work was supported by National Institutes of Health (R.M., R.H.) and Howard Hughes Medical Institute (R.H.). We thank members of the Malinow laboratory for helpful discussions, Helen Hsieh and Simon Rumpel for careful reading of this manuscript, and N. Dawkins for expert technical assistance.

Correspondence should be addressed to Roberto Malinow, 1 Cold Spring Harbor, Cold Spring Harbor Laboratory, Cold Spring Harbor, NY 11724. E-mail: malinow@cshl.org.

Copyright $\odot 2003$ Society for Neuroscience $\quad 0270-6474 / 03 / 239220-09 \$ 15.00 / 0$
}

tein interaction sites, including a PDZ [postsynaptic density 95 (PSD-95)/Discs large/zona occludens-1] type II ligand. Three GluR2-interacting PDZ domain partners, GRIP (glutamate receptor-interacting protein), ABP (AMPA-binding protein), and PICK1 (PKC-interacting protein 1), have been identified by several groups (Dong et al., 1997; Srivastava et al., 1998; Dev et al., 1999; Wyszynski et al., 1999; Xia et al., 1999). GRIP and ABP are highly homologous multi-PDZ domain proteins that colocalize with GluR2 at synapses and within dendritic compartments (Srivastava et al., 1998; Wyszynski et al., 1999; Burette et al., 2001). PICK1 was originally identified as a protein that interacts with protein kinase C- $\alpha$ (PKC $\alpha$ ) (Staudinger et al., 1995; Staudinger et al., 1997) and was subsequently shown to interact with the C terminus of GluR2 and GluR3 and to colocalize with these receptors at synapses (Dev et al., 1999; Xia et al., 1999). GluR2-PDZ interactions, and in particular those between GluR2 and GRIP/ABP, appear to be critical for synaptic AMPA-R localization because elimination of the PDZ binding domain of the receptor or competitive inhibition of PDZ interactions with GluR2 C-tail peptides reduce or eliminate the presence of GluR2 at synapses (Dong et al., 1997; Osten et al., 2000; Shi et al., 2001). Interestingly, phosphorylation of GluR2 serine 880 (S880) disrupts the interaction with GRIP/ABP but not with PICK1 (Matsuda et al., 1999, 2000; Chung et al., 2000). Phorbol ester treatment of neurons leads to phosphorylation of S880, recruits PICK1 to excitatory synapses, and promotes internalization of AMPA receptors (Chung et al., 2000). These results suggest that phosphorylation of S880 disrupts GluR2-GRIP/ABP interaction and leads to receptor internalization. The hypothesis that 
PICK1-GluR2 interaction leads to receptor internalization is consistent with studies showing that disrupting this interaction specifically inhibits long-term depression (LTD) in both the cerebellum (Xia et al., 2000) and hippocampus (Kim et al., 2001). Nevertheless, other groups have found that disruption of GluR2GRIP/ABP interaction increases baseline synaptic transmission, inhibits LTD (Daw et al., 2000), and reduces internalization of GluR2 (Braithwaite et al., 2002).

The evidence to date has led to two conflicting models of the physiological role of GluR2-PDZ partner interactions and their modulation by S880 phosphorylation. In one model, GluR2GRIP/ABP interaction is required for receptor stabilization at the synapse. Disruption of this interaction by $\mathrm{S} 880$ phosphorylation results in the removal of the receptor from the synapse by facilitating GluR2-PICK1 interactions (Xia et al., 2000; Kim et al., 2001; Perez et al., 2001). In this model, phosphorylation of GluR2 S880 can mediate LTD. The second model holds that S880 phosphorylation disrupts intracellular retention of GluR2 by GRIP/ $\mathrm{ABP}$ and thereby allows receptors to be delivered to the synapse. GluR2 receptors phosphorylated at $\mathrm{S} 880$ would thus constitute a pool of receptors rapidly cycling to and from the synapse (Daw et al., 2000; Braithwaite et al., 2002). In this model, GluR2 S880 phosphorylation can reverse LTD, causing de-depression. These models generate different predictions about the effect of S880 phosphorylation on GluR2 incorporation into synapses.

To distinguish between these models, we determined the fate of GluR2 homomeric receptors containing mutations that mimicked or prevented phosphorylation of GluR2 at S880 in organotypic hippocampal slice cultures. The use of a previously described "electrophysiological tag" assay (Hayashi et al., 2000) allowed us to determine the presence or absence of mutated receptors at synapses and their effect on synaptic transmission and plasticity. We show that mimicking GluR2 S880 phosphorylation prevents stable synaptic incorporation of receptors, reduces transmission, and partially occludes LTD. Preventing GluR2 S880 phosphorylation permits stable synaptic incorporation of the receptors and reduces LTD. Our results thus support the first model, in which phosphorylation of GluR2 S880 plays an important role in LTD.

\section{Materials and Methods}

Generation and expression of recombinant receptors. The green fluorescent protein (GFP)-tagged GluR2(R607Q) receptor was generated and introduced into a Sindbis viral vector as described previously (Shi et al., 1999). Briefly, the GFP coding sequence [enhanced GFP (EGFP); Clontech, Palo Alto, CA] was inserted after the predicted signal peptide cleavage site for GluR2. Point mutations at GluR2 serine 880 (S880E) and lysine 882 (K882A) were generated in a pSinRep5-GluR2(R607Q) construct using the QuickChange mutagenesis system (Stratagene, La Jolla, CA). The constructs were verified by sequence analysis.

The GluR2-GFP constructs were expressed in CA1 neurons in rat hippocampal organotypic slice cultures using the Sindbis virus expression system. Such expression generates homomeric receptors that show rectification (Shi et al., 1999). A recent study has indicated that the (R607Q) mutation can enhance the maturation of GluR2-containing receptors (Greger et al., 2002), which raises the question of whether this mutation may affect synaptic trafficking of the receptor. It is unlikely, however, that synaptic trafficking of homomeric GluR2 receptors is perturbed by the R607Q mutation in our preparation because the fraction of synaptic transmission accounted for by homomeric (R607Q) receptors (Shi et al., 2001) is the same as that of endogenous GluR2/GluR3 heteromers [as inferred by disrupting native GluR2 C-tail interactions with peptides or expression of the GluR2 C-tail (Shi et al., 2001)]. Slices were prepared from postnatal 6- to 7-d-old animals, infected after 5-12 d in culture, and cells were recorded $\sim 36 \mathrm{hr}$ after Sindbis virus infection.
Electrophysiology. Experiments were performed at $29^{\circ} \mathrm{C}$ in physiological artificial CSF, pH 7.4, and, unless otherwise stated, contained the following (in mM): $119 \mathrm{NaCl}, 2.5 \mathrm{KCl}, 4 \mathrm{CaCl}_{2}, 4 \mathrm{MgCl}_{2}, 26 \mathrm{NaHCO}_{3}, 1$ $\mathrm{NaH}_{2} \mathrm{PO}_{4}, 1 \mathrm{NaHPO}_{4}, 11$ D-glucose, 0.1 picrotoxin, 0.1 DL-APV, and 0.001 2-chloroadenosine (gassed with 5\% $\mathrm{CO}_{2}-95 \% \quad \mathrm{O}_{2}$ ). 2-Chloroadenosine was included to prevent bursting. DL-APV was not included during LTD induction protocols. Patch recording pipettes (2.5-5 M $\Omega$ ) were filled with internal solution, $\mathrm{pH} 7.25$, containing the following (in mM): 115 cesium methanesulfonate, $20 \mathrm{CsCl}, 10 \mathrm{HEPES}$, $2.5 \mathrm{MgCl}_{2}, 4 \mathrm{Na}_{2} \mathrm{ATP}, 0.4 \mathrm{Na}_{3} \mathrm{GTP}, 10$ sodium phosphocreatine, and 0.6 EGTA. Whole-cell voltage-clamp recordings were made with Axopatch-1D amplifiers (Axon Instruments, Foster City, CA). Synaptic responses were evoked using two bipolar stimulating electrodes with single voltage pulse ( $200 \mu \mathrm{S}$, up to $2 \mathrm{~V})$. The stimulating electrodes were placed over Schaffer collateral fibers $75-150 \mu \mathrm{m}$ to either side of CA1 cell bodies in the horizontal dimension and at least $100 \mu \mathrm{m}$ away in the vertical dimension. The stimulating electrodes were separated by at least $100 \mu \mathrm{m}$ in the vertical dimension to stimulate independent pathways, and responses were evoked with a stimulation frequency of $0.7 \mathrm{~Hz}$. Synaptic AMPA-R-mediated responses at $-60,40$, and $0 \mathrm{mV}$ were averaged over 70-100 trials for each pathway, and the ratio of -60 to $40 \mathrm{mV}$ responses was used as an index of rectification. In general, when comparing the amplitude of synaptic transmission, pairs of neighboring uninfected and infected cells were recorded simultaneously. In some cases, recordings were first made in an infected or uninfected cell, and, afterward, a second recording was made in an adjacent uninfected or infected cell using identical stimulation settings. Cells were visualized for wholecell patch-clamp recording, using infrared differential interference contrast illumination. Infected cells were identified using epifluorescence illumination (Shi et al., 1999). LTD was induced by holding the cell at $-40 \mathrm{mV}$ and giving 500 stimuli at $1 \mathrm{~Hz}$. For experiments in which rectification was determined after LTD induction, APV was washed in after the induction of LTD. Differences in LTD were analyzed by comparing mean normalized values during a $10 \mathrm{~min}$ interval after the induction of LTD. In peptide infusion experiments with p-SVKI [KKEGYNVYGIES$\left.\left(\mathrm{PO}_{4}\right)-\mathrm{VKI}\right]$, the peptide was included in the internal solution at a concentration of $200 \mu \mathrm{M}$, and the protease inhibitors leupeptin and bestatin (Roche Molecular Biochemicals, Hertforshire, UK) were each included at a concentration of $100 \mu \mathrm{M}$. p-SVKI was synthesized and purified at the Howard Hughes Medical Institute biopolymer facility (The Johns Hopkins University School of Medicine). Peptides were infused for $10 \mathrm{~min}$ while recording evoked responses at a holding potential of $-60 \mathrm{mV}$, after which responses were recorded at a holding potential of $+40 \mathrm{mV}$ to measure rectification in the cell. In the peptide infusion experiments, the rectification value was calculated by dividing the mean of the last 100 responses collected at a holding potential of $-60 \mathrm{mV}$, by the mean of 100 responses collected at $+40 \mathrm{mV}$. Results are reported as mean $\pm \mathrm{SEM}$, and statistical significance was set at $p<0.05$. Statistical difference of means was calculated using a two-tailed, unpaired $t$ test for unpaired measurements and a two-tailed, paired $t$ test for paired measurements.

Immunoblot and biochemical studies of GluR2 K882A. Hippocampal slice cultures were infected with Sindbis virus expressing either GluR2(R607Q)-GFP or GluR2(R607, K882A)-GFP. After 36 hr, slice cultures were rapidly frozen and subsequently lysed in ice-cold buffer containing $10 \mathrm{~mm}$ sodium phosphate, $\mathrm{pH}$ 7.0, $100 \mathrm{~mm} \mathrm{NaCl}, 10 \mathrm{~mm}$ sodium pyrophosphate, $50 \mathrm{~mm} \mathrm{NaF}, 1 \mathrm{~mm}$ sodium orthovanadate, $5 \mathrm{~mm}$ EDTA, $5 \mathrm{~mm}$ EGTA, $10 \mu \mathrm{g} / \mathrm{ml}$ leupeptin, $1 \mu \mathrm{g} / \mathrm{ml}$ aprotinin, $10 \mu \mathrm{g} / \mathrm{ml}$ phenylmethylsulfonylfluoride (PMSF), and $10 \mu \mathrm{g} / \mathrm{ml}$ pepstatin (two slices per sample). Lysates were sonicated and centrifuged to obtain a membranous pellet. The pellet was washed by two additional cycles of resuspension and centrifugation. Pellets were then suspended in SDS sample buffer, and equal volumes were loaded in duplicate on a $7.5 \%$ polyacrylamide gel. Western blotting was performed with a polyclonal GluR2 C-terminal antibody, as well as a new GluR2 phosphoserine- 880 antibody purified from previously obtained crude polyclonal antiserum (Chung et al., 2000). To purify anti-phosphoserine- 880 antibody that would recognize phosphorylation in the presence or absence of a neighboring mutation at lysine-882 (K882A), an affinity column was made by coupling a bovine serum albumin (BSA)-conjugated GluR2 K882A peptide (KVYGIES- 


\section{A GluR2(R607Q)-GFP}
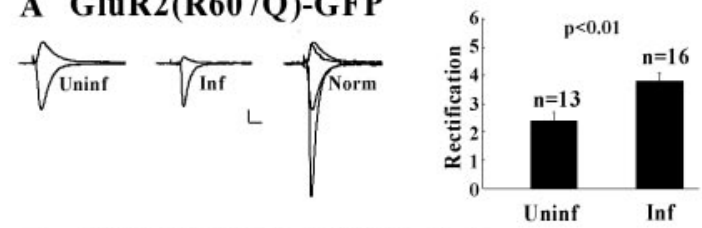

B GluR2(R607Q,S880E)-GFP

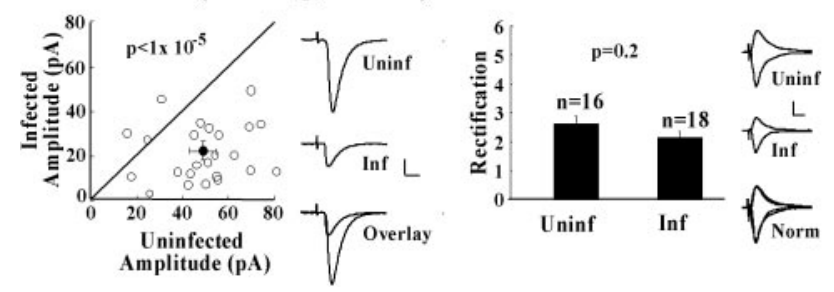

Figure 1. GluR2 receptor unable to bind GRIP/ABP is not delivered to synapses and depresses synaptic transmission. A, GluR2(R6070)-GFP is delivered to synapses. Left, Sample traces of synaptic responses at membrane potentials of -60 and $+40 \mathrm{mV}$ are shown for uninfected and infected cells, and the responses normalized to the value at $+40 \mathrm{mV}$. Calibration: $20 \mathrm{pA}, 20$ msec. Right, Comparison of rectification values in uninfected cells and infected cells. B, A mutated receptor, GluR2 (R607Q, S880E)-GFP, that does not interact with GRIP/ABP is not delivered to synapses and depresses synaptic transmission. Left, Synaptic response amplitudes of pairs of uninfected versus infected cells plus sample traces of synaptic responses at $-60 \mathrm{mV}$ of uninfected and infected cells and overlay comparison. Calibration: 20 pA, $10 \mathrm{msec}$. Right, Comparison of rectification in uninfected and infected cells and sample traces from uninfected (Uninf), infected (Inf), and the normalized response overlay (Norm).

VKI) to Affigel-10 resin (Bio-Rad, Hercules, CA). Phospho-specificity of this antibody was confirmed by Western blotting on serial dilutions of BSA-GluR2 K882A peptide (10, 5, and $2.5 \mathrm{ng}$ ) treated with lambda phosphatase.

To study binding of different forms of GluR2 to the PDZ proteins PICK1 and GRIP1, GluR2 constructs were cotransfected into human embryonic kidney 293T (HEK293T) cells along with pEGFP-C1 (GFP), GRIP1 cDNA subcloned into pEGFP-N1 (GFP-GRIP1), or PICK1 cDNA subcloned into pEGFP-C3 (GFP-PICK1) using Lipofectamine 2000 reagent. After $48 \mathrm{hr}$, cells were harvested in ice-cold immunoprecipitation (IP) buffer (25 mм Tris, pH 7.4, 100 mм NaCl, 5 mм EDTA, 5 mм EGTA, $1 \mu \mathrm{M}$ okadaic acid, $50 \mathrm{~mm} \mathrm{NaF}, 1 \mathrm{~mm}$ sodium vanadate, and $1 \%$ Triton $\mathrm{X}-100)$ with an added protease inhibitor mixture (10 $\mu \mathrm{g} / \mathrm{ml}$ leupeptin, 1 $\mu \mathrm{g} / \mathrm{ml}$ aprotinin, $10 \mu \mathrm{g} / \mathrm{ml}$ PMSF, and $10 \mu \mathrm{g} / \mathrm{ml}$ pepstatin). Cell lysates ( $1 \mathrm{ml}$ ) were precleared with $50 \mu \mathrm{l}$ of a 1:1 slurry of Protein A-Sepharose (Amersham Biosciences, Arlington Heights, IL)/IP buffer for $1 \mathrm{hr}$ at $4^{\circ} \mathrm{C}$. At the same time, anti-GFP monoclonal antibody (Molecular Probes, Eugene, OR) was precoupled to Protein A-Sepharose by incubating $3 \mu \mathrm{g}$ of antibody with $50 \mu \mathrm{l}$ of a 1:1 slurry of Protein A-Sepharose/IP buffer for $1 \mathrm{hr}$ at $4^{\circ} \mathrm{C}$. Aliquots $(20 \mu \mathrm{l})$ of precleared lysates $(2 \%)$ were saved as input. Precleared lysates were then incubated with antibody-bound Sepharose beads for $3 \mathrm{hr}$ at $4^{\circ} \mathrm{C}$. Beads were washed three times in IP buffer with $1 \mathrm{~mm}$ PMSF and eluted with SDS sample buffer. Inputs and immunoprecipitated samples were loaded in duplicate on separate $7.5 \%$ acrylamide gels and analyzed by Western blotting with rabbit anti-GFP polyclonal antibody and rabbit anti-GluR2 $\mathrm{N}$-terminal antibody.

\section{Results}

GluR2 receptors that lack GRIP/ABP interaction do not stably incorporate into synapses

Expression of "electrophysiologically tagged" GluR2 with wildtype C-tail, GluR2(R607Q)-GFP, in CA1 pyramidal cells resulted in a significant increase in the rectification of evoked synaptic responses relative to those from uninfected cells (Fig. $1 A$ ). This confirms synaptic incorporation of recombinant homomeric GluR2 recombinant receptors (Shi et al., 2001). Previous work has shown that recombinant homomeric receptor replaces the endogenous recycling pool of GluR2/GluR3 receptors without changing the amplitude of synaptic transmission (Shi et al., 2001). Mutation of the native GluR2 PDZ ligand sequence SVKI to EVKI, which mimics serine phosphorylation, has been shown previously to abolish binding to GRIP/ABP but not PICK1 (Chung et al., 2000). We expressed a GluR2 subunit, GluR2(R607Q, S880E)-GFP, containing this mutation and then measured its effects on rectification and the amplitude of synaptic transmission. No significant difference in rectification of synaptic responses was observed in cells expressing GluR2(R607Q, S880E)-GFP versus those from uninfected cells (Fig. $1 B$ ). This indicates that the recombinant receptor was not incorporated into synapses. Specifically abolishing the PDZ-mediated GluR2GRIP/ABP interaction thus prevents stable synaptic incorporation of GluR2 homomers. We predict that endogenous GluR2/ GluR3 heteromers, which behave like recombinant GluR2 homomers (Shi et al., 2001), would show similar regulation.

\section{Mimicking GluR2 S880 phosphorylation depresses synaptic transmission}

To assess quantitatively the effect of GluR2(R607Q, S880E)-GFP trafficking on the amplitude of synaptic transmission, recordings were made simultaneously from neighboring uninfected and recombinant receptor-expressing neurons. A significant decrease in synaptic transmission was observed in cells expressing GluR2(R607Q, S880E)-GFP (Fig. 1B). It thus follows that, although this receptor itself is not incorporated into synapses, it acts in a dominant-negative manner on synaptic transmission to the expressing cell. The depression of synaptic transmission can be attributed to the $S 880 \mathrm{E}$ mutation because a previous study did not observe any depressive effect in GluR2(R607Q)-GFPexpressing cells (Shi et al., 2001). GluR2(R607Q, S880E)-GFP receptors are functional, as verified by expressing them in baby hamster kidney cells. As expected, inwardly rectifying currents were observed in response to puffed kainate applications (data not shown).

\section{Infusion of a PICK1-binding peptide rescues synaptic delivery of GluR2(R607Q, S880E)-GFP}

A critical issue regarding the lack of synaptic delivery of GluR2(R607Q, S880E)-GFP is the step at which trafficking of this receptor is affected. One possibility is that the receptor is transiently inserted at the synaptic surface but, because of its failure to interact with GRIP/ABP, is quickly removed via its interaction with PICK1. To test this hypothesis, we infused cells expressing GluR2(R607Q, S880E)-GFP with p-SVKI, a 10 amino acid phospho-peptide that encompasses the GluR2 C-tail PDZ ligand phosphorylated at S880 and specifically binds to PICK1. This peptide can increase transmission, presumably by disrupting GluR2-PICK1 interaction and blocking endocytosis and/or by releasing a sequestered pool of GluR2 (Kim et al., 2001). The peptide was infused in cells expressing GluR2(R607Q, S880E)GFP, and rectification was assayed as described. A small but significant increase in the amplitude of synaptic transmission at $-60 \mathrm{mV}$ was observed (Fig. $2 A)(p=0.025$; Student's $t$ test; $n=$ 30) In addition, a highly significant increase in rectification relative to uninfected cells was also noted. This increased rectification is in contrast to what is observed in cells expressing GluR2(R607Q, S880E)-GFP that were not perfused with p-SVKI (Fig. $1 B$ ). Synaptic delivery of GluR2(R607Q, S880E)-GFP can therefore be detected when its interaction with PICK1 is inhibited. These results are consistent with the view that, after S880 phosphorylation, GluR2/GluR3 receptors are destabilized at synapses, and PICK1 plays a role in their rapid removal. 


\section{GluR2(R607Q,S880E)-GFP + p-SVKI infusion}

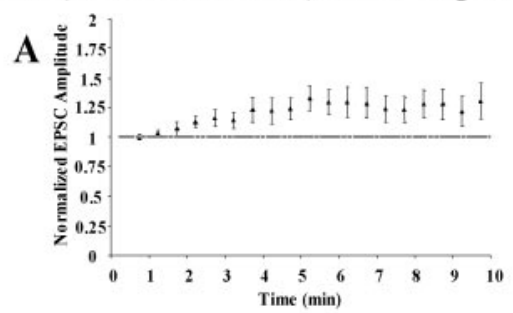

B

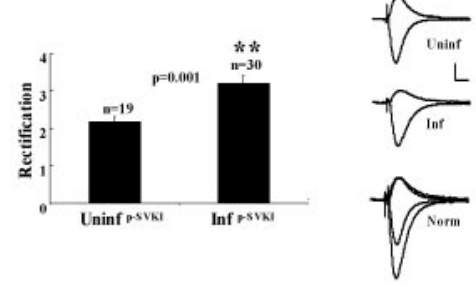

Figure 2. Infusion of $p$-SVKI rescues the synaptic function of GluR2(R607Q, S880E)-GFP. A, p-SVKI infusion in cells expressing GluR2(R607Q, S880E)-GFP increases the amplitude of transmission at $-60 \mathrm{mV}$. Synaptic responses are plotted over time as p-SVKI $(200 \mu \mathrm{M})$ is infused through the patch pipette ( $p<0.05 ; t$ test; $n=30$ ). B, GluR2(R607Q, S880E)-GFP is detected at synapses. Comparison of rectification in uninfected cells versus cells expressing GluR2(R607Q, S880E)-GFP, both of which were infused with p-SVKI peptide $(200 \mu \mathrm{M})$. On the left are sample traces of uninfected (Uninf), GluR2(R607Q, S880E)-GFP infected (Inf), and $+40 \mathrm{mV}$ response overlay of infected cell responses normalized to the synaptic response at $+40 \mathrm{mV}$ relative to the uninfected response (Norm). Calibration: 20 pA, $10 \mathrm{msec}$.

\section{Preventing S880 phosphorylation of GluR2 permits stable synaptic incorporation}

Having shown that mimicking GluR2 S880 phosphorylation prevented stable synaptic incorporation of GluR2 homomers, we then determined the effect of preventing phosphorylation of this residue. The GluR2 S880 residue lies within the sequence ESVKI, which matches a PKC consensus site (S/T-X-K/R) (Kishimoto et al., 1985; Woodgett et al., 1986). The basic residue within the motif is critical to recognition by PKC, as is the case with several serine/threonine protein kinase consensus sites (Kreegipuu et al., 1998). Mutation of the lysine (K) to an alanine (A) residue would therefore be expected to prevent phosphorylation of this site. To test this, GluR2(R607Q)-GFP and GluR2(R607Q, K882A)-GFP were each expressed in hippocampal slice cultures. Immunoblot analysis of slice culture lysates was performed with a phosphorylation state-specific antibody to $S 880$ (Chung et al., 2000). To exclude interfering effects of the K882A mutation on phosphorylation state-specific recognition by the antibody at $\mathrm{S880}$, crude antiserum was repurified on an affinity column containing the K882A point mutation (Fig. $3 A$ ). Phosphorylation of the K882A mutant was not observed (Fig. $3 B$ ), in contrast to both endogenous GluR2 and expressed GluR2(R607Q)-GFP. Coimmunoprecipation analysis in transfected HEK293T cells confirmed that both GRIP1 and PICK1 binding to GluR2 K882A is intact (Fig. 4). GluR2(R607Q, K882A)-GFP, thus, cannot be phosphorylated at S880, but it remains competent to bind GRIP/ABP and PICK1.

We recorded from neurons expressing GluR2(R607Q, K882A)-GFP and detected a significant increase in the rectification of synaptic transmission when compared with that of uninfected cells. This indicates that this receptor was stably incorporated into synapses (Fig. 5). We also compared the data for rectification in GluR2(R607Q, K882A)-GFP cells with those in GluR2(R607Q)-GFP cells, by normalizing each data set to the corresponding mean uninfected rectification value. No significant difference in rectification was observed between cells ex-
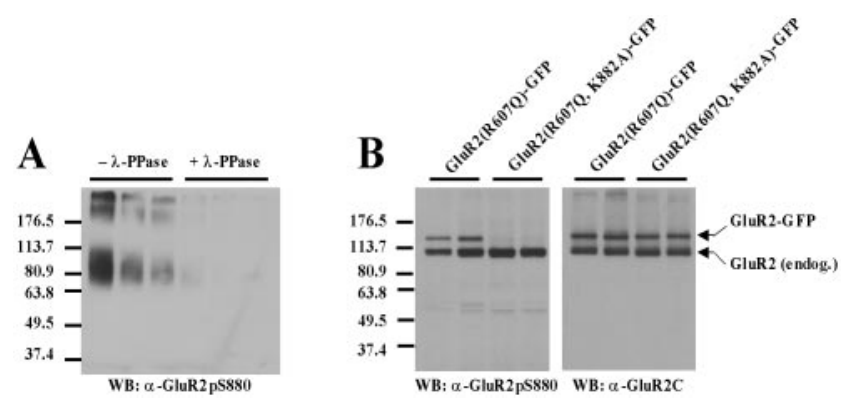

Figure 3. Mutation of GluR2 $\mathrm{K} 882$ to alanine prevents phosphorylation at $\mathrm{S} 880$ in vivo. $A$, Lambda phosphatase ( $\lambda$-PPase) treatment on serial dilutions of BSA-conjugated GluR2K882A peptide. The BSA peptide conjugate is the same as that used to purify the antibody. Elimination of immunorecognition during treatment at all concentrations shown indicates phosphospecificity. The "smear" seen on the gel (in lanes with no treatment) reflects variability in the extent of BSA conjugation to the peptide during the coupling process. $B$, Immunoblots of lysates from slices infected with either GluR2(R607Q)-GFP or GluR2 (R607Q, K882A)-GFP. Left, Probing with the $S 880$ phospho-specific antibody indicates phosphorylation of endogenous GluR2 but no phosphorylation of recombinant GFP-GluR2 subunits containing the K882A mutation (lanes shown in duplicate). Right, Probing with an polyclonal antibody raised to the C-terminal 20 amino acids of GluR2 confirms expression of both GluR2(R607Q)-GFP and GluR2 (R607Q, K882A)-GFP in infected slices. WB, Western blot.

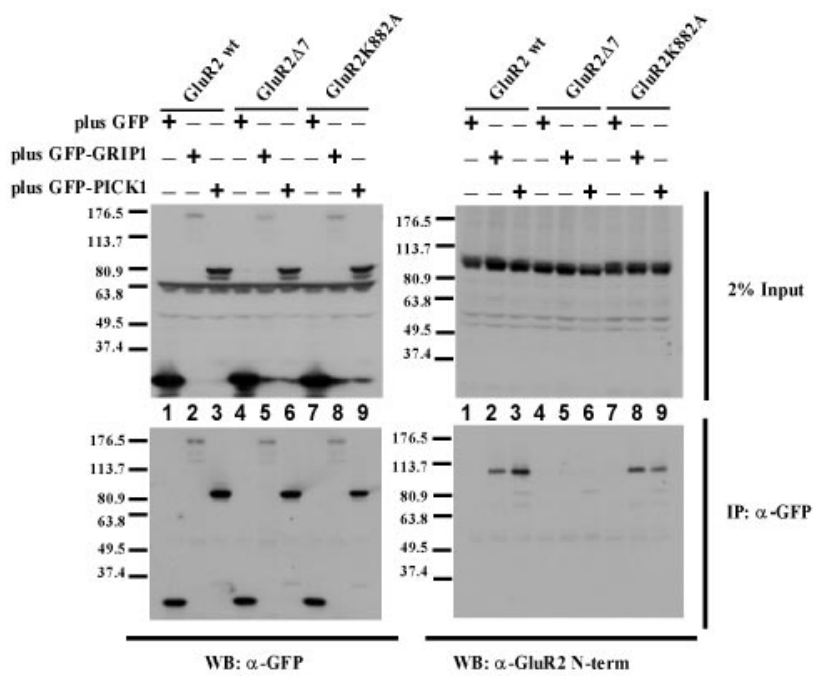

Figure 4. GluR2 K882A mutation does not disrupt binding to GRIP1 or PICK1 in transfected HEK293T cells. HEK293T cells were cotransfected with various forms of GluR2 and GFP alone, GFP-GRIP1, or GFP-PICK1 (+ / - indicates cotransfection of GFP, GFP-GRIP1, or GFP-PICK1 with a particular form of GluR2 in that lane). Top, Inputs for immunoprecipitation (IP) were probed with anti-GFP polyclonal antibody (top left) and anti-GluR2 N-terminal polyclonal antibody (top right). GFP-tagged proteins can be observed in the input around the following molecular weight markers: GFP-GRIP1, 176.5 kDa; GFP-PICK1, 80.9 kDa; and GFP, <37.4 kDa. Nonspecific anti-GFP immunoreactivity is seen in all lanes at $\sim 63.8 \mathrm{kDa}$. GluR2 wild type, GluR2 with the (-terminal 7 amino acids deleted (GluR2 $\Delta 7$ ), and GluR2 K882A can all be detected in the input between the 80.9 and $113.7 \mathrm{kDa}$ markers. Bottom, GFP-tagged proteins were immunoprecipitated with anti-GFP monoclonal antibody and probed with anti-GFP polyclonal antibody (bottom left) and anti-GluR2 N-terminal polyclonal antibody (bottom right). Both GluR2 wild type and GluR2 K882A coimmunoprecipitate with GFP-GRIP1 (lanes 2 and 8) and GFP-PICK1 (lanes 3 and 9) but not with GFP alone (lanes 1 and 7 ). GluR2 $\Delta 7$ lacking the C-terminal PDZ ligand does not coimmunoprecipitate with GFP, GFP-GRIP1, or GFPPICK1 (lanes 4-6). WB, Western blot.

pressing GluR2(R607Q)-GFP or GluR2(R607Q, K882A)-GFP. The amplitude of synaptic transmission measured at $-60 \mathrm{mV}$ in GluR2(R607Q, K882A)-GFP-expressing cells was indistinguishable from that of neighboring uninfected cells (Fig. 5). 


\section{GluR2(R607Q,K882A)-GFP}
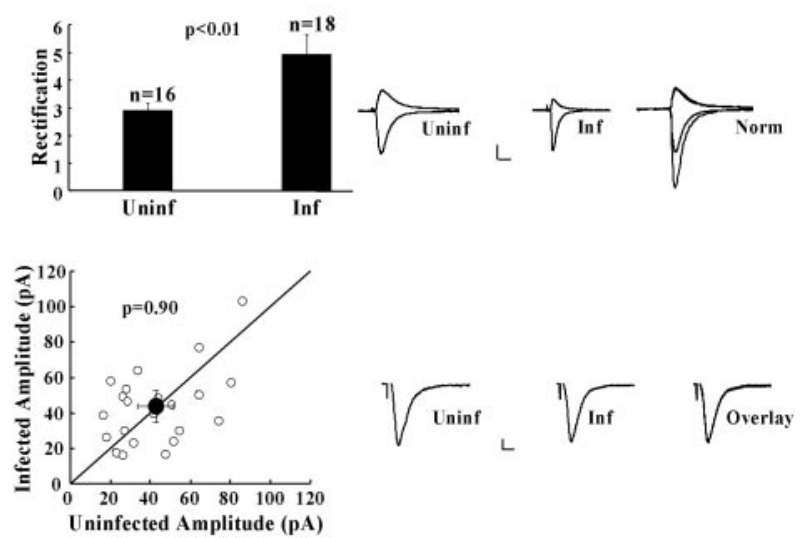

Figure 5. GluR2 receptors impaired in $\$ 880$ phosphorylation are delivered to synapses and do not affect the amplitude of synaptic transmission. Top, Comparison of rectification in uninfected and infected cells and sample traces from uninfected (Uninf), infected (Inf), and the normalized response overlay (Norm). Calibration: 20 pA, 20 msec. Bottom, Synaptic response amplitudes of pairs of uninfected versus infected cells plus sample traces of synaptic responses at $-60 \mathrm{mV}$ of uninfected and infected cells and overlay comparison. Calibration: $5 \mathrm{pA}, 10 \mathrm{msec}$.

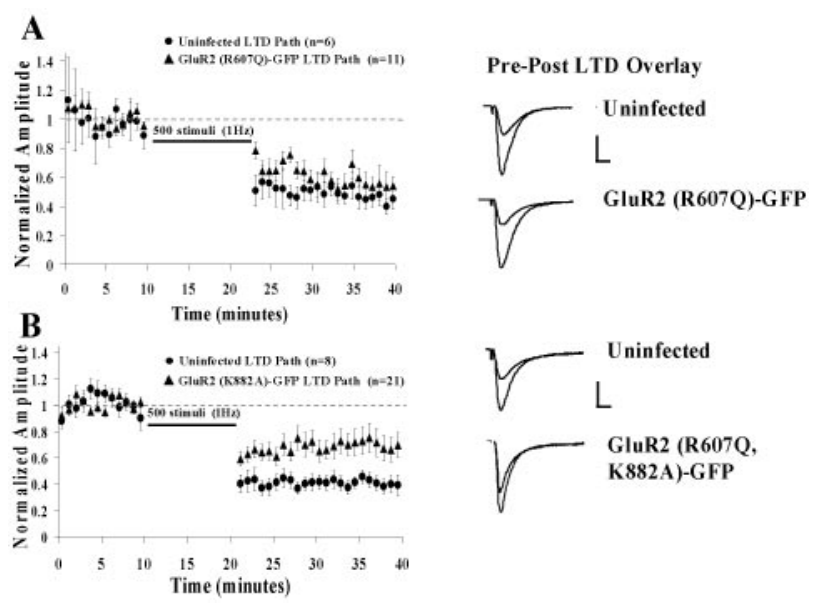

Figure 6. LTD is inhibited in cells expressing $\$ 880$ phosphorylation-deficient GluR2 receptors. $A$, Normalized mean synaptic responses before and after LTD in uninfected cells and cells expressing GluR2(R6070)-GFP. Sample average traces of uninfected and infected cells are shown with overlays of responses of before and after LTD induction. Calibration: $20 \mathrm{pA}, 20 \mathrm{msec}$. B, Same as above comparing uninfected cells and cells expressing GluR2(R607Q, K882A)-GFP. Calibration: $20 \mathrm{pA}, 20 \mathrm{msec}$.

\section{Preventing GluR2S880 phosphorylation inhibits long-term depression}

NMDA receptor-dependent LTD, a well characterized form of synaptic plasticity in the hippocampus, involves removal of AMPA-Rs from the synapse via clathrin-dependent endocytosis (Luthi et al., 1999; Beattie et al., 2000; Lin et al., 2000; Man et al., 2000; Xia et al., 2000). We wanted to test the possibility that $S 880$ phosphorylation, and interruption of GluR2-GRIP/ABP interaction, was required to remove AMPA-Rs from synapses during LTD. First, we compared LTD in cells expressing GluR2(R607Q)GFP versus uninfected cells. We found that LTD was indistinguishable in these two groups (Fig. 6A). In contrast, LTD was significantly impaired in cells expressing GluR2(R607Q, K882A)GFP (Fig. 6B). This finding implies that phosphorylation at $\mathrm{S} 880$

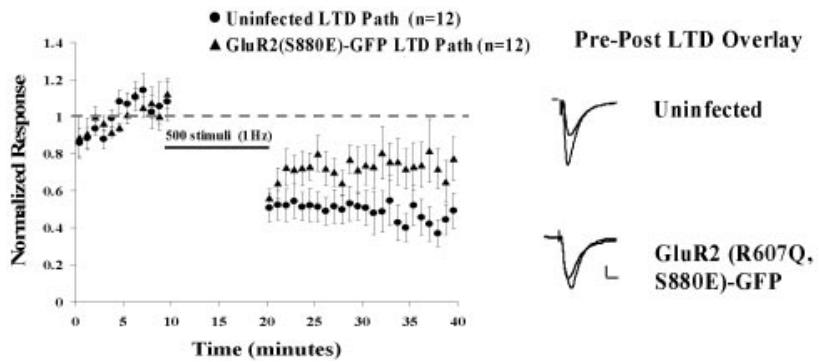

Figure 7. LTD is attenuated in cells expressing GluR2 receptors with S880E mimicking phosphorylation. Normalized mean synaptic responses before and after LTD in uninfected cells and cells expressing GluR2(R607Q, S880E)-GFP. Sample average traces of uninfected and infected cells are shown with overlays of responses before and after LTD induction. Calibration: $20 \mathrm{pA}$, $20 \mathrm{msec}$.

and a disruption of GluR2-GRIP/ABP interaction play a role in the mechanism of LTD.

\section{Mimicking GluR2S880 phosphorylation partially occludes} long-term depression

We also examined LTD in cells expressing GluR2(R607Q, S880E)-GFP. As indicated above, these cells showed depressed synaptic transmission. We wanted to determine whether this depression was occurring by a mechanism related to or independent of that underlying LTD. LTD was significantly attenuated in cells expressing the GluR2(R607Q, S880E)-GFP receptor (Fig. 7) $(p=0.035)$. If the $\mathrm{S} 880 \mathrm{E}$ receptor depressed transmission by a mechanism wholly independent of that underlying LTD, it would be expected that the effects would be additive. The fact that S880E trafficking partially occluded LTD implies that these processes share at least some mechanism in common. LTD is thus likely to depress transmission, at least in part, by affecting trafficking of GluR2 receptors.

\section{Long-term depression removes GluR2 homomers \\ from synapses}

The data presented up to now are consistent with the view that LTD removes GluR2 receptors by inducing phosphorylation at S880. We sought to test directly whether LTD removes such receptors. We showed previously that homomeric rectifying GluR2 receptors are incorporated continuously into synapses. We could thus test whether these receptors are removed from synapses after LTD by measuring rectification after LTD. As a control, we monitored transmission in a control pathway in which LTD was not induced. We recorded cells expressing GluR2(R607Q)-GFP and induced LTD in one pathway. Ten minutes after LTD induction, APV was added, and rectification was determined in both the depressed and control pathways. Indeed, a significantly lower rectification was observed in the depressed pathway compared with that of either the control pathway or pathways in GluR2(R607Q) cells under basal stimulation conditions (Fig. 8). Furthermore, the level of rectification in the depressed path was indistinguishable from that observed in uninfected cells, indicating that all recombinant receptors were removed from synapses after LTD. Finally, in cells expressing GluR2(R607Q, K882A)GFP, the LTD induction protocol did not result in a difference in rectification between the control and LTD pathways (data not shown), consistent with the impairment in LTD observed in cells expressing this receptor. These data show unambiguously that GluR2 homomers are removed from synapses during LTD in a pathway-specific manner. 


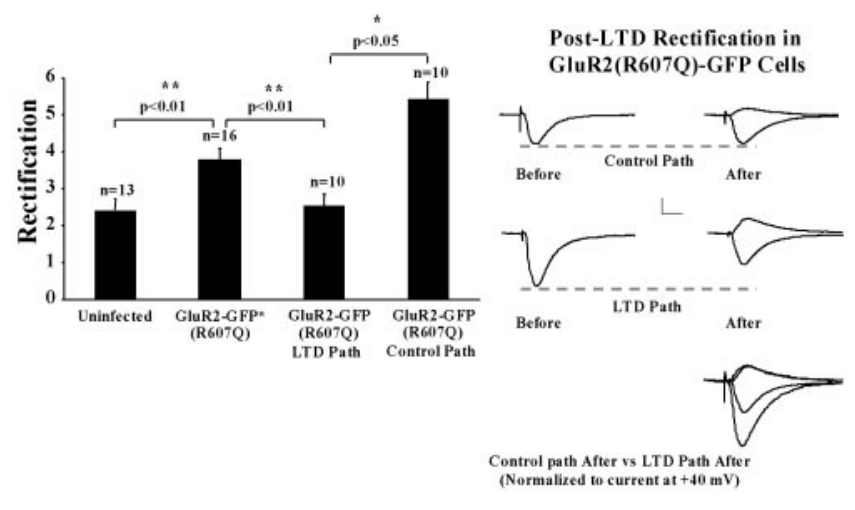

Figure 8. LTD removes synaptic GluR2 receptors. Left, Comparison of rectification values in uninfected cells, GluR2(R6070)-GFP-expressing cells during basal stimulation, and after LTD (separate group of cells). Note that data for the first two columns are the same as for Figure 1 and are included for comparison. Right, Sample traces of GluR2(R6070)-GFP infected before and after LTD from control and depressed pathways.

\section{Discussion}

There is now broad experimental support for the notion that GluR2/GluR3 heteromeric receptors continually cycle between nonsynaptic and synaptic sites in hippocampal pyramidal neurons as a consequence of ongoing exocytotic and endocytotic processes (for review, see Malinow and Malenka, 2002). The steady-state number of AMPA-Rs at a synapse can be reduced by signaling triggered by NMDA-Rs and mediated by Rap/ p38MAPK (mitogen-activated protein kinase) cascades (Zhu, 2002) that also involve phosphatases (Mulkey et al., 1993, 1994; Morishita et al., 2001). GluR2 interactions with the PDZ domain partners GRIP/ABP and PICK1 and, in particular, the role of S880 phosphorylation in modulating these interactions have been suggested previously to be important in GluR2 trafficking and in long-term depression (Daw et al., 2000; Xia et al., 2000; Kim et al., 2001). Studies to date, however, have not been in agreement regarding the role played by the GluR2-GRIP/ABP interaction versus that of GluR2-PICK1. The approach taken here was to express GluR2 subunits with mutations that mimic or prevent S880 phosphorylation and then determine the consequences on receptor trafficking, the amplitude of synaptic transmission, and LTD in an organotypic hippocampal slice culture system.

A GluR2 subunit deficient in GRIP/ABP binding but competent to bind PICK1, GluR2(R607Q, S880E)-GFP, was not functionally detected at synapses as indicated by the rectification assay. This finding implies that the interaction of GluR2 with GRIP/ $\mathrm{ABP}$ is necessary for functional incorporation of the receptor to the synapse. In principle, this could be attributable to either a failure of receptor insertion into the synapse or a failure to anchor the receptor at the synaptic surface before being internalized rapidly by endocytosis via its interaction with PICK1. To distinguish between these possibilities, we eliminated GluR2-PICK1 interactions by infusion of a phosphopeptide, p-SVKI (Kim et al., 2001), into cells expressing GluR2(R607Q, S880E)-GFP. In the presence of p-SVKI, the GluR2(R607Q, S880E)-GFP receptor was now detected at the synapse. It is likely that, by eliminating PICK1 binding, endocytosis of GluR2 present at the synaptic surface is slowed-eliminated, and therefore even the GRIP-bindingdeficient GluR2(R607Q, S880E)-GFP receptor can accumulate. If GRIP/ABP-GluR2 interaction was critical for insertion of the receptor at the synapse, elimination of PICK1 interaction with p-SVKI would not rescue synaptic GluR2(R607Q, S880E)-GFP.
This result supports a role of GRIP/ABP in anchoring GluR2 at the synapse after receptor insertion and PICK1 playing a role in rapid endocytosis of unanchored receptor. This interpretation of GRIP/ABP function is consistent with the findings of a study in which GRIP/ABP interaction-deficient GluR2 receptors were imaged in cultured hippocampal neurons (Osten et al., 2000). It was shown that the mutated GluR2 receptors, incapable of binding to GRIP/ABP, accumulated at synapses to a much lower extent than wild-type GluR2 receptors.

In addition to the fact that the GluR2(R607Q, S880E)-GFP receptor was not detected at synapses, depression of synaptic transmission was also evident. The dominant-negative effect of the mutated receptor on synaptic transmission is probably attributable to the fact that this receptor is still competent to undergo trafficking steps before anchoring at the synapse and thus can effectively compete with native receptors for access to limited insertion machinery. The fact that recombinant receptors are overexpressed further supports this argument. We conclude that GluR2-GRIP/ABP interactions are indispensable for the stable and functional synaptic incorporation of GluR2/GluR3 heteromers in hippocampal CA1 pyramidal cells.

We explored the role of GluR2 S880 phosphorylation in LTD by expressing GluR2 constructs that prevented or mimicked phosphorylation at this site. We reasoned that, if GluR2 S880 phosphorylation is necessary for LTD, then preventing phosphorylation of S880 would block or reduce LTD. Conversely, if mimicking phosphorylation resulted in depression of synaptic transmission through the mechanism normally used by LTD, additional depression by LTD would not be observed (i.e., it would be occluded).

Blocking GluR2 S880 phosphorylation did not affect basal transmission, but it did significantly diminish LTD. We conclude from this that, during LTD, an increase in GluR2 S880 phosphorylation favors the formation of GluR2-PICK1 complexes and thereby increases the net rate of GluR2 internalization. This interpretation is consistent with a study showing that GluR2 S880 phosphorylation is increased after LTD induction (Kim et al., 2001). Furthermore, infusion of a peptide that selectively blocked GluR2-PICK1 interaction also inhibited LTD (Kim et al., 2001). We also examined the effect of mimicking GluR2 S880 phosphorylation on LTD. LTD in GluR2(R607Q, S880E)-GFP-expressing cells was also diminished. We interpret this result as a partial occlusion of LTD by the S880E mutated receptor given that expression of this receptor depresses synaptic transmission during basal stimulation. Given that LTD was not completely inhibited or occluded by the mutated GluR2 receptors used in this study, it is likely that additional mechanisms operate. For instance, the other dominant form of AMPA-R at synapses, GluR1/GluR2, might be removed after LTD through separate mechanisms (Lee et al., 2000). It is unlikely, however, that this process depends on interactions mediated by GluR1 cytoplasmic tail, because expression of the GluR1 C-tail failed to block LTD (Shi, 2001). It is possible that regulated palmytoylation of PSD-95 (El-Husseini et al., 2002), which can interact with AMPA-Rs through stargazin (Schnell et al., 2002), could participate in removal of receptors during LTD. Finally, we also tested whether LTD removes receptors from synapses using electrophysiologically tagged receptors. This experiment is analogous to one in which homomeric GluR1 receptors are driven into synapses by LTP (Hayashi et al., 2000). Here, we expressed electrophysiologically tagged GluR2 receptors that are continually incorporated into synapses. After LTD, we saw no more evidence for their functional presence at synapses. This indicates that LTD can functionally remove GluR2 
Model of the Synaptic Role of GluR2 S880 Phosphorylation
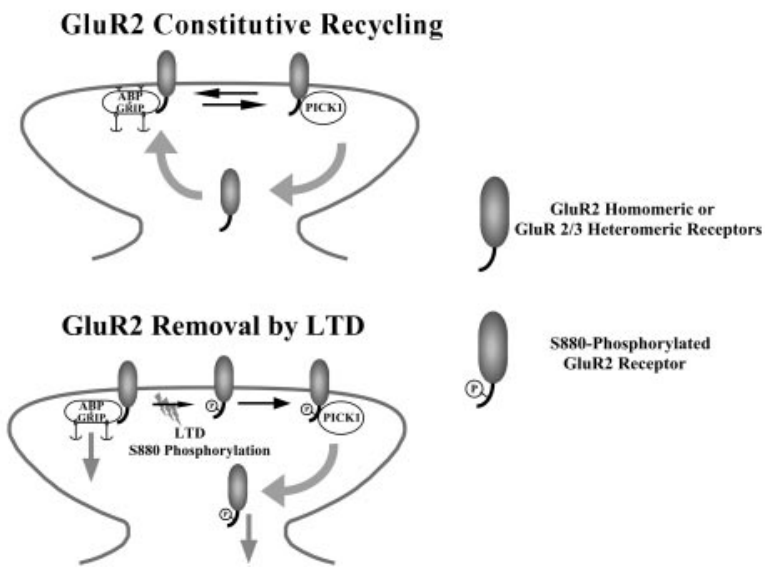

Figure 9. Model of GluR2/GluR3 heteromeric receptor trafficking during basal synaptic activity and after LTD induction. During basal synaptic activity, GluR2/GluR3 heteromeric receptors are inserted at the synapse where they can interact with either GRIP/ABP, which stabilizes them at the synaptic surface for some time, or with PICK1, which primes them for endocytosis. The equilibrium between GluR2-GRIP/ABP and GluR2-PICK1 binding primarily determines the steady-state number of synaptic AMPA-Rs. During LTD, GluR2S880 phosphorylation (P) prevents interaction of the receptor with GRIP/ABP, so that the formation of GluR2-PICK1 complexes is facilitated and endocytosis of the receptor is accelerated. As a result, the number of synaptic AMPA-Rs is decreased, and synaptic transmission is depressed. Maintenance of the depression may be mediated by removal of GRIP/ABP anchoring sites from the synapse. Phosphorylated receptors could also be sorted into a nonrecycling compartment and/or degraded.

homomers from synapses. Physical removal of the receptor is supported by imaging studies (Beattie et al., 2000). Recently, distinct roles of NSF ( $N$-ethylmaleimide-sensitive factor) and the AP2 (adaptor protein-2) complex in receptor endocytosis and LTD have been characterized (Lee et al., 2002). The AP2 complex and NSF bind to overlapping sites encompassed by GluR2 membrane-proximal amino acids $844-853$. NSF binds specifically to amino acids $849-853$, and AP2 interacts with amino acids $844-848$. Interestingly, infusion of a peptide that competes specifically with the GluR2-NSF interaction results in a rundown of basal synaptic transmission but does not block the subsequent induction of LTD. In contrast, interfering with the GluR2-AP2 interaction has no effect on basal synaptic transmission but effectively blocks the induction of LTD. These results suggest that NSF is critical to the maintenance of basal synaptic transmission, whereas AP2-GluR2 interaction is involved in the net removal of GluR2 receptors during LTD. Given that disruption of GluR2PICK1 interaction by peptide infusion both increases baseline transmission and blocks LTD (Kim et al., 2001), it is likely that PICK1 function intersects with both constitutive and regulated endocytotic pathways. Our conclusions are summarized by the model outlined in Figure 9. In the absence of plasticity-inducing stimuli, GluR2/GluR3 heteromers are inserted at the synapse in which they can interact with GRIP/ABP. This PDZ interaction anchors a fraction of the receptors at the synapse in which they are optimally positioned to bind presynaptically released glutamate. Receptors can also interact with PICK1, which may prime them for endocytosis. This model postulates that, as receptors are removed from the synapse, unbound GRIP/ABP anchoring sites are filled by newly inserted GluR2/GluR3 heteromers. In this scenario, an equilibrium is maintained between GRIP/ABPbound receptors and PICK1-bound receptors. During LTD and subsequent to GluR2 S880 phosphorylation, this equilibrium is shifted in favor of the GluR2-PICK1 interaction so that the rate of GluR2 internalization exceeds the insertion rate into the synapse. This perturbation leads to a net loss of synaptic receptors and thus a decrease in synaptic transmission. It is possible that GRIP/ ABP anchoring sites not filled with AMPA receptors are unstable and removed. This would reduce the available incorporation sites for GluR2/GluR3 receptors and be a mechanism for LTD maintenance. An additional possibility would be the sorting of internalized AMPA-Rs into different pools depending on their phosphorylation state (Beattie et al., 2000; Ehlers, 2000; Lin et al., 2000).

The present findings complement those of Kim et al. (2001). Here we show that blocking GluR2-GRIP/ABP interaction by mimicking phosphorylation at S880 selectively leads to a depression of synaptic transmission that partially occludes LTD. Preventing S880 phosphorylation in our study reduces LTD. In their study, increased phosphorylation at $\mathrm{S} 880$ is detected during LTD, and selective disruption of GluR2-PICK1 interaction blocks LTD. In addition, it has been shown recently in GluR2 knock-out (KO) mice that the rescue of cerebellar LTD critically depends on GluR2 S880 phosphorylation (Chung et al., 2003). It is notable, however, that in the GluR2 KO mouse, cerebellar LTD is completely absent (Chung et al., 2003), whereas hippocampal LTD is still detected (Jia et al., 1996). The latter result is consistent with the fact that, in the current work, the GluR2 S880 mutant receptors did not block LTD completely, consistent with additional LTD pathways operating in the hippocampus.

Our results appear to be at odds with studies that have argued for a model in which GRIP/ABP serve primarily to retain an intracellular, noncycling pool of GluR2 receptors. In one study (Daw et al., 2000), done in acute hippocampal slices, infusion of a peptide that disrupts GluR2-GRIP/ABP interactions increased baseline synaptic transmission, whereas a peptide that selectively disrupts GluR2-PICK1 interaction had no effect. This contrasts with work in which identical peptides were used but in which a consistent increase in baseline transmission was observed with either peptide (Kim et al., 2001). Another study examined the effects of various mutations on GluR2 cell surface expression in cultured hippocampal neurons and argued that preventing GRIP/ABP interaction decreased the fraction of GluR2 receptors that remained internalized after endocytosis (Braithwaite et al., 2002). Because total surface expression of the receptor was examined in that study, it is difficult to compare those results with the present ones because we examined effects of GluR2 mutations only on synaptic GluR2 function.

Interestingly, a recent study has found and characterized a palmitolyated form of ABP-L, which they term p-ABP-L (DeSouza et al., 2002). The authors examined the distribution of transfected ABP-L, p-ABP-L, and GluR2 in cultured hippocampal neurons. It was found that $\mathrm{p}-\mathrm{ABP}-\mathrm{L}$ was consistently localized to dendritic spines and colocalized with GluR2 on the plasma membrane. In contrast, the unpalmitoylated ABP-L was found in intracellular compartments of dendritic shafts and the cell body and colocalized with intracellular GluR2. A palmitoylated form of GRIP (GRIP 1b) has also been reported (Yamazaki et al., 2001). It is possible that depalmitoylation of GRIP/ABP during LTD removes synaptic anchoring sites for GluR2/GluR3 receptors. Also, the differential localization of GRIP/ABP isoforms may perhaps explain some of the apparent discrepancies in the literature concerning the role of GluR2-ABP interaction. It is conceivable that contrasting effects on synaptic transmission will be observed under differing experimental conditions that affect the ratio of 
palmitoylated and unpalmitoylated isoforms and/or the subcellular access of competing peptides to them.

In summary, this study supports two main conclusions. First, phosphorylation of GluR2 at S880 can limit the contribution of this receptor to synaptic transmission, presumably by interrupting interactions with GRIP/ABP and promoting endocytosis. Second, phosphorylation at S880 is a critical step in LTD.

\section{References}

Beattie EC, Carroll RC, Yu X, Morishita W, Yasuda H, von Zastrow M, Malenka RC (2000) Regulation of AMPA receptor endocytosis by a signaling mechanism shared with LTD. Nat Neurosci 3:1291-1300.

Braithwaite SP, Xia H, Malenka RC (2002) Differential roles for NSF and GRIP/ABP in AMPA receptor cycling. Proc Natl Acad Sci USA 99:7096-7101.

Burette A, Khatri L, Wyszynski M, Sheng M, Ziff EB, Weinberg RJ (2001) Differential cellular and subcellular localization of ampa receptorbinding protein and glutamate receptor-interacting protein. J Neurosci 21:495-503.

Chung HJ, Xia J, Scannevin RH, Zhang X, Huganir RL (2000) Phosphorylation of the AMPA receptor subunit GluR2 differentially regulates its interaction with PDZ domain-containing proteins. J Neurosci 20:7258-7267.

Chung HJ, Steinberg JP, Huganir RL, Linden DJ (2003) Requirement of AMPA receptor GluR2 phosphorylation for cerebellar long-term depression. Science 300:1751-1755.

Daw MI, Chittajallu R, Bortolotto ZA, Dev KK, Duprat F, Henley JM, Collingridge GL, Isaac JT (2000) PDZ proteins interacting with C-terminal GluR2/3 are involved in a PKC-dependent regulation of AMPA receptors at hippocampal synapses. Neuron 28:873-886.

DeSouza S, Fu J, States BA, Ziff EB (2002) Differential palmitoylation directs the AMPA receptor-binding protein $\mathrm{ABP}$ to spines or to intracellular clusters. J Neurosci 22:3493-3503.

Dev KK, Nishimune A, Henley JM, Nakanishi S (1999) The protein kinase C alpha binding protein PICK1 interacts with short but not long form alternative splice variants of AMPA receptor subunits. Neuropharmacology 38:635-644.

Dingledine R, Borges K, Bowie D, Traynelis SF (1999) The glutamate receptor ion channels. Pharmacol Rev 51:7-61.

Dong H, O’Brien RJ, Fung ET, Lanahan AA, Worley PF, Huganir RL (1997) GRIP: a synaptic PDZ domain-containing protein that interacts with AMPA receptors. Nature 386:279-284.

Ehlers MD (2000) Reinsertion or degradation of AMPA receptors determined by activity-dependent endocytic sorting. Neuron 28:511-525.

El-Husseini AE, Schnell E, Dakoji S, Sweeney N, Zhou Q, Prange O, Gauthier-Campbell C, Aguilera-Moreno A, Nicoll RA, Bredt DS (2002) Synaptic strength regulated by palmitate cycling on PSD-95. Cell 108:849-863.

Greger IH, Khatri L, Ziff EB (2002) RNA editing at arg607 controls AMPA receptor exit from the endoplasmic reticulum. Neuron 34:759-772.

Hayashi Y, Shi SH, Esteban JA, Piccini A, Poncer JC, Malinow R (2000) Driving AMPA receptors into synapses by LTP and CaMKII: requirement for GluR1 and PDZ domain interaction. Science 287:2262-2267.

Hollmann M, Heinemann S (1994) Cloned glutamate receptors. Annu Rev Neurosci 17:31-108.

Jia Z, Agopyan N, Miu P, Xiong Z, Henderson J, Gerlai R, Taverna FA, Velumian A, MacDonald J, Carlen P, Abramow-Newerly W, Roder J (1996) Enhanced LTP in mice deficient in the AMPA receptor GluR2. Neuron 17:945-956.

Kim CH, Chung HJ, Lee HK, Huganir RL (2001) Interaction of the AMPA receptor subunit GluR2/3 with PDZ domains regulates hippocampal long-term depression. Proc Natl Acad Sci USA 98:11725-11730.

Kishimoto A, Nishiyama K, Nakanishi H, Uratsuji Y, Nomura H, Takeyama Y, Nishizuka Y (1985) Studies on the phosphorylation of myelin basic protein by protein kinase $\mathrm{C}$ and adenosine $3^{\prime}: 5^{\prime}$-monophosphatedependent protein kinase. J Biol Chem 260:12492-12499.

Kreegipuu A, Blom N, Brunak S, Jarv J (1998) Statistical analysis of protein kinase specificity determinants. FEBS Lett 430:45-50.

Lee HK, Barbarosie M, Kameyama K, Bear MF, Huganir RL (2000) Regula- tion of distinct AMPA receptor phosphorylation sites during bidirectional synaptic plasticity. Nature 405:955-959.

Lee SH, Liu L, Wang YT, Sheng M (2002) Clathrin adaptor AP2 and NSF interact with overlapping sites of GluR2 and play distinct roles in AMPA receptor trafficking and hippocampal LTD. Neuron 36:661-674.

Lin JW, Ju W, Foster K, Lee SH, Ahmadian G, Wyszynski M, Wang YT, Sheng M (2000) Distinct molecular mechanisms and divergent endocytotic pathways of AMPA receptor internalization. Nat Neurosci 3:1282-1290.

Luscher C, Xia H, Beattie EC, Carroll RC, von Zastrow M, Malenka RC, Nicoll RA (1999) Role of AMPA receptor cycling in synaptic transmission and plasticity. Neuron 24:649-658.

Luthi A, Chittajallu R, Duprat F, Palmer MJ, Benke TA, Kidd FL, Henley JM, Isaac JT, Collingridge GL (1999) Hippocampal LTD expression involves a pool of AMPARs regulated by the NSF-GluR2 interaction. Neuron 24:389-399.

Malinow R, Malenka RC (2002) AMPA receptor trafficking and synaptic plasticity. Annu Rev Neurosci 25:103-126.

Malinow R, Mainen ZF, Hayashi Y (2000) LTP mechanisms: from silence to four-lane traffic. Curr Opin Neurobiol 10:352-357.

Man YH, Lin JW, Ju WH, Ahmadian G, Liu L, Becker LE, Sheng M, Wang YT (2000) Regulation of AMPA receptor-mediated synaptic transmission by clathrin-dependent receptor internalization. Neuron 25:649-662.

Matsuda S, Mikawa S, Hirai H (1999) Phosphorylation of serine-880 in GluR2 by protein kinase $\mathrm{C}$ prevents its $\mathrm{C}$ terminus from binding with glutamate receptor-interacting protein. J Neurochem 73:1765-1768.

Matsuda S, Launey T, Mikawa S, Hirai H (2000) Disruption of AMPA receptor GluR2 clusters following long-term depression induction in cerebellar Purkinje neurons. EMBO J 19:2765-2774.

Morishita W, Connor JH, Xia H, Quinlan EM, Shenolikar S, Malenka RC (2001) Regulation of synaptic strength by protein phosphatase 1 . Neuron 32:1133-1148.

Mulkey RM, Herron CE, Malenka RC (1993) An essential role for protein phosphatases in hippocampal long-term depression. Science 261:1051-1055.

Mulkey RM, Endo S, Shenolikar S, Malenka RC (1994) Involvement of a calcineurin/inhibitor-1 phosphatase cascade in hippocampal long-term depression. Nature 369:486-488.

Osten P, Srivastava S, Inman GJ, Vilim FS, Khatri L, Lee LM, States BA, Einheber S, Milner TA, Hanson PI, Ziff EB (1998) The AMPA receptor GluR2 C terminus can mediate a reversible, ATP- dependent interaction with NSF and alpha- and beta-SNAPs. Neuron 21:99-110.

Osten P, Khatri L, Perez JL, Köhr G, Giese G, Daly C, Schulz TW, Wensky A, Lee LM, Ziff EB (2000) Mutagenesis Reveals a Role for ABP/GRIP Binding to GluR2 in Synaptic Surface Accumulation of the AMPA Receptor. Neuron 27:313-325.

Passafaro M, Piech V, Sheng M (2001) Subunit-specific temporal and spatial patterns of AMPA receptor exocytosis in hippocampal neurons. Nat Neurosci 4:917-926.

Perez JL, Khatri L, Chang C, Srivastava S, Osten P, Ziff EB (2001) PICK1 targets activated protein kinase $C \alpha$ to AMPA receptor clusters in spines of hippocampal neurons and reduces surface levels of the AMPA-type glutamate receptor subunit 2. J Neurosci 21:5417-5428.

Rosenmund C, Stern-Bach Y, Stevens CF (1998) The tetrameric structure of a glutamate receptor channel. Science 280:1596-1599.

Schnell E, Sizemore M, Karimzadegan S, Chen L, Bredt DS, Nicoll RA (2002) Direct interactions between PSD-95 and stargazin control synaptic AMPA receptor number. Proc Natl Acad Sci USA 99:13902-13907.

Seeburg PH (1993) The Trends Neurosci/TiPS lecture: the molecular biology of mammalian glutamate receptor channels. Trends Neurosci 16:359-365.

Shi S (2001) Molecular mechanisms for synaptic regulation of AMPA receptors. PhD thesis, State University of New York, Stony Brook.

Shi S, Hayashi Y, Esteban JA, Malinow R (2001) Subunit-specific rules governing ampa receptor trafficking to synapses in hippocampal pyramidal neurons. Cell 105:331-343.

Shi SH, Hayashi Y, Petralia RS, Zaman SH, Wenthold RJ, Svoboda K, Malinow R (1999) Rapid spine delivery and redistribution of AMPA receptors after synaptic NMDA receptor activation. Science 284:1811-1816.

Song I, Kamboj S, Xia J, Dong H, Liao D, Huganir RL (1998) Interaction of the N-ethylmaleimide-sensitive factor with AMPA receptors. Neuron 21:393-400.

Srivastava S, Osten P, Vilim FS, Khatri L, Inman G, States B, Daly C, DeSouza S, Abagyan R, Valtschanoff JG, Weinberg RJ, Ziff EB (1998) Novel an- 
chorage of GluR2/3 to the postsynaptic density by the AMPA receptorbinding protein ABP. Neuron 21:581-591.

Staudinger J, Zhou J, Burgess R, Elledge SJ, Olson EN (1995) PICK1: a perinuclear binding protein and substrate for protein kinase $\mathrm{C}$ isolated by the yeast two-hybrid system. J Cell Biol 128:263-271.

Staudinger J, Lu J, Olson EN (1997) Specific interaction of the PDZ domain protein PICK1 with the $\mathrm{COOH}$ terminus of protein kinase C-alpha. J Biol Chem 272:32019-32024.

Wenthold RJ, Petralia RS, Blahos J, II, Niedzielski AS (1996) Evidence for multiple AMPA receptor complexes in hippocampal CA1/CA2 neurons. J Neurosci 16:1982-1989.

Woodgett JR, Gould KL, Hunter T (1986) Substrate specificity of protein kinase C. Use of synthetic peptides corresponding to physiological sites as probes for substrate recognition requirements. Eur J Biochem 161:177-184. Wyszynski M, Valtschanoff JG, Naisbitt S, Dunah AW, Kim E, Standaert DG,
Weinberg R, Sheng M (1999) Association of AMPA receptors with a subset of glutamate receptor-interacting protein in vivo. J Neurosci 19:6528-6537.

Xia J, Zhang X, Staudinger J, Huganir RL (1999) Clustering of AMPA receptors by the synaptic PDZ domain-containing protein PICK1. Neuron 22:179-187.

Xia J, Chung HJ, Wihler C, Huganir RL, Linden DJ (2000) Cerebellar longterm depression requires PKC-regulated interactions between GluR2/3 and PDZ domain-containing proteins. Neuron 28:499-510.

Yamazaki M, Fukaya M, Abe M, Ikeno K, Kakizaki T, Watanabe M, Sakimura K (2001) Differential palmitoylation of two mouse glutamate receptor interacting protein 1 forms with different $\mathrm{N}$-terminal sequences. Neurosci Lett 304:81-84.

Zhu JJ (2002) Ras and Rap control AMPA receptor trafficking during synaptic plasticity. Cell 110:443-455. 